\title{
Clinical and radiological cervical spine evaluation in retired professional rugby players
}

\author{
David Brauge, MD, ${ }^{1,2}$ Cyrille Delpierre, PhD, ${ }^{3}$ Philippe Adam, MD, ${ }^{4}$ Jean Christophe Sol, MD, PhD, ${ }^{1,2}$ \\ Pierre Bernard, MD, ${ }^{5}$ and Franck-Emmanuel Roux, MD, PhD ${ }^{1,2}$ \\ 1Pôle Neuroscience-Neurochirurgie, Hôpital de Purpan et Faculté de Médecine, 2Université Paul Sabatier; 3UMR 1027, \\ INSERM-Université Paul Sabatier Toulouse III Faculté de Médecine Toulouse Purpan; ${ }^{4}$ Clinique Médipôle Garonne, Toulouse; \\ and ${ }^{5}$ Centre Aquitain du Dos, Mérignac, France
}

OBJECT Acute cervical spine injuries have been extensively studied in high-level contact sports. However, the relation between the appearance of degenerative cervical spine disease and the exposure to repeated trauma in such sports as rugby is still unclear. Using clinical and MRI evaluation, we aimed to determine if former professional rugby players had more serious degenerative cervical spine symptoms than the general population.

METHODS Two groups, one composed of 101 former rugby players (all men, mean age 40.3 years, range 35-47 years, SD 2.3 years) and the other of 85 male volunteers serving as a control group (mean age 41.6 years, range 35-49 years, SD 4.5 years) were studied. The former rugby players were evaluated on average 5.8 years after retirement (range 1-16 years, SD 3.5 years). The groups were matched in terms of sex, age, job, current sports training, and smoking habits. Each participant received a complete neurological evaluation. Clinical symptoms were evaluated using the Japanese Orthopaedic Association (JOA) questionnaire, and chronic neck pain was specifically evaluated using a visual analog scale (VAS) and the Neck Disability Index (NDI). Overall, $25 \mathrm{MRI}$ studies were performed in each group. MRI studies, including dynamic sequences, focused on degenerative lesions (Matsumoto score and canal diameter) and on muscular and medullary morphological analysis.

RESULTS Significantly more former rugby players than controls complained of chronic neck pain (51 [50.50\%] of 101 vs 27 [31.76\%] of 85, $p=0.01)$. Rugby players also had significant reductions of neck mobility. Nevertheless, in those complaining of pain, there was no statistically significant difference between groups with respect to VAS and NDI scores ( $p$ $=0.57$ ). On MRI, former rugby players had a narrower vertebral canal (on average $0.88 \pm 0.167 \mathrm{~cm}$ vs $0.99 \pm 0.130 \mathrm{~cm}$, $p=0.007)$ and more foraminal stenosis $(p=0.01)$. No significant difference in the Matsumoto score was found between the 2 groups with respect to other degenerative lesions. Former rugby players had more often undergone surgery for a degenerative condition than had members of the control group (10 cases vs 0 in the control group, $p=0.0021$ ).

CONCLUSIONS A few years after retirement, former professional rugby players seem to have more frequent cervical spine pain and MRI degenerative lesions, such as foraminal stenosis and narrowing of the spinal canal, compared with controls who had not been professional rugby players. A longer evaluation is necessary to determine if these findings persist over time.

http://thejns.org/doi/abs/10.3171/2015.1.SPINE14594

KEY WORDS rugby; degenerative cervical spine; collision sport; former athletes; cervical stenosis; discopathy; football

A CUTE cervical spine injuries in contact sports are a major issue and sometimes have devastating consequences. ${ }^{1,4,27}$ However, the question of potential long-term degenerative disorders of the spine in athletes practicing sports at a high level has not been thoroughly studied so far, even though some authors suggest in- creased risk of early degeneration and some clinical consequences. ${ }^{3,13,23}$ Rugby, also called rugby football, is one of those sports that put strain on the cervical spine. This sport is practiced by men and women in more than 100 countries across 5 continents. Since the beginning of professionalism (in 1995 in France), high-level players have

ABBREVIATIONS APD = anteroposterior diameter; ISCO = International Standard Classification of Occupations; JOA = Japanese Orthopaedic Association; MCR = medulla-to-cervical canal ratio; NDI = Neck Disability Index; VAS = visual analog scale.

SUBMITTED June 14, 2014. ACCEPTED January 8, 2015.

INCLUDE WHEN CITING Published online July 21, 2015; DOI: 10.3171/2015.1.SPINE14594.

DISCLOSURE This study was supported by funding from the Fédération Française de Rugby, Ligue Nationale de Rugby, Institut de Recherche sur la Moelle Epinière et l'Encéphale (IRME), Société Française de Chirurgie du Rachis (SFCR), and Centre Hospitalier Universitaire de Toulouse. 
been subjected to increasing workloads, which has resulted in increases in the number of injuries and paid sick days. ${ }^{9}$ Although the medical follow-up of these athletes has become progressively specialized, it remains very difficult to determine which long-term consequences are due to these constant stresses on the musculoskeletal system, especially on the cervical spine.

The number of retired professional rugby players is increasing. The aim of our study was to determine whether degenerative cervical spine disease is more frequent and/ or more serious in former rugby players several years after retirement than in the general population. We performed a comparative study, evaluating a large group of 101 former professional rugby players and a control group from the general population.

\section{Methods}

\section{Retired Rugby Players Group}

Our study group comprised 101 former professional rugby players identified through the French professional rugby players' union (Provale). We included men between 35 and 47 years old (mean age 40.4 years, SD 2.3 years). The inclusion criteria for the former rugby players were at least 1 year of professional contract (mean career duration 16.4 years, range 8-25 years, SD 3.1 years) and having been retired from any rugby activity for at least 1 year (mean duration of retirement 5.8 years, range 1-16 years, SD 3.5 years). All but one of the retired rugby players were working in other fields. The demographic variables studied were age when starting to play rugby, age at first appearance in a senior team, position in field, national selection, and age at retirement. All the former athletes contacted agreed to participate in the study.

\section{Control Group}

The control group, made up of 85 male volunteers recruited from the general population, was matched with the study group for sex, age, job, smoking habit, and current duration of weekly sport training. The baseline characteristics of the control group are shown in Table 1. The controls had never practiced rugby in competition or any other sport at professional level. For this control group, results regarding height, weight, smoking, and level of physical activity were the same as in French epidemiological surveys. ${ }^{2,15}$ Jobs were classified using the International Standard Classification of Occupations (ISCO) provided by the International Labor Organization and categorized in 10 groups. Most of our controls and former rugby players were managers, health professionals, or associate health professionals (groups 1,2, and 3 of the ISCO). No statistically significant difference was detected between the 2 groups in terms of job classification (Table 2).

\section{Exclusion Criteria}

Exclusion criteria for the former rugby players and controls were neurodegenerative disease, inflammatory rheumatism, and cervical spine trauma within the last 3 months. We also excluded all former rugby players and all potential controls with a history of surgery for traumatic reason (e.g., cervical fractures, traumatic disc herniation).
None of them had a job with a risk of neck pain defined by at least one of the following: stereotyped, repetitive task, use of vibrating machines, working with hands above shoulders, and prolonged flexion of the cervical spine. For both groups, we excluded people with a medical history of cervical spine infection or spinal tumor or malformation (except for congenital single-level fusion).

\section{MRI Study Groups}

We planned to perform 50 MRI studies. This number was calculated before the beginning of the study in light of previously published data and to match the statistical requisites. Twenty-five of the former rugby players were matched with 25 controls who consented to a cervical spine MRI study. These 2 MRI groups were matched in terms of sex, age, job, smoking habits, and duration of weekly sport training. Volunteers had to have given their consent at recruitment. The characteristics of these subgroups are detailed in Table 3.

\section{Clinical Data Acquisition}

The primary complaint assessed was chronic neck pain. Study participants were considered to have chronic neck pain if they had had at least 1 occurrence per month for at least 6 months (including radiculalgia). The pain severity was evaluated by means of a visual analog scale (VAS). Cervical disability was evaluated by means of the Neck Disability Index (NDI). Disabling neck pain was defined by an NDI score $>15$. A complete neurological assessment was made using the Japanese Orthopaedic Association (JOA) questionnaire. Accurate history of cervical spine surgery for degenerative disease was also recorded. Finally, cervical spine range of motion was measured with a tape measure according to an anatomical landmark. Flexion/extension and right and left rotations were evaluated by the distance between the chin and the suprasternal notch and the chin and the acromioclavicular joint, respectively. Left and right tilt was measured between the external acoustic meatus and acromioclavicular joint. Clinical data collection was standardized and included in an Excel database. All the participants were examined by the same investigator (D.B.).

\section{MRI Data Acquisition}

The radiological comparison concerned the anteroposterior diameter (APD) of the spinal canal and the medullato-cervical canal ratio (MCR) at the narrowest level between the occipitocervical junction and T1-2. Dynamic sequences completed the acquisition, searching for loss of cerebrospinal fluid anterior and posterior to the spinal cord during flexion and/or extension of the neck. We also performed a comparison using the Matsumoto score. ${ }^{17}$ This score evaluates degenerative changes based on disc degeneration, anterior and/or posterior disc protrusion, narrowing of the disc space, and foraminal stenosis. We searched for the existence of an intramedullary lesion (high T2-weighted imaging signal intensity or syringomyelia).

Finally, an evaluation of the paraspinal muscles was also planned. For practical reasons, our study was limited 
TABLE 1. Characteristics of 101 former rugby players and 85 controls (all males)*

\begin{tabular}{lccc}
\hline \multicolumn{1}{c}{ Characteristic } & Former Rugby Players & Controls & $p$ Value \\
\hline Age (yrs) & $40.4 \pm 2.9$ & $41.6 \pm 4.5$ & 0.09 \\
\hline Smoker & $33 / 101$ & $21 / 85$ & 0.18 \\
\hline Weekly duration of training (min) & $145.1 \pm 161.2$ & $99.8 \pm 151.6$ & 0.06 \\
\hline Height (cm) & $183.7 \pm 7.5$ & $177.7 \pm 6.5$ & $<0.001$ \\
\hline BMl & $29.64 \pm 3.83$ & $25.30 \pm 3.83$ & $<0.001$ \\
\hline Age when starting rugby (yrs) & $9.3 \pm 3.9$ & $\mathrm{NA}$ & \\
\hline Age at 1st appearance in senior team (yrs) & $18.0 \pm 1.4$ & $\mathrm{NA}$ & \\
\hline Age at retirement (yrs) & $34.5 \pm 2.9$ & $\mathrm{NA}$ & \\
\hline Career duration (yrs) & $16.4 \pm 3.1$ & $\mathrm{NA}$ & \\
\hline No. of yrs since retiring from rugby & $5.8 \pm 3.5$ & $\mathrm{NA}$ & \\
\hline No. of international players & 45 & 85 & \\
\hline Total & 101 & & \\
\hline BMal
\end{tabular}

$\mathrm{BMI}=$ body mass index; NA = not applicable.

* Means are presented with standard deviations. Bold type indicates statistical significance. The 2 groups were matched in terms of sex, age, weekly duration of sport training, jobs, and tobacco consumption. As expected, former rugby players were taller and heavier than controls.

to one cervical extensor muscle (right splenius capitis). The analysis consisted of manually tracing defined regions of interest over a cross-sectional view of this muscle, carefully avoiding nearby fat, on axial T1-weighted images (1 image per participant) obtained at the C6-7 level and produced by OsiriX software (V4.1.2 Apple).

MRI sequences were obtained in 3 different centers, but the imaging protocol was designed so that data were comparable among centers. All examinations were performed by 2 physicians, a radiologist and a neurosurgeon, using a blind protocol. The average of the 2 measures was used for the analysis.

\section{Ethics Considerations}

Written informed consent was obtained from each participant. This study was approved by the regional ethics committee (Comité de Protection des Personnes Sud Ouest et Outre Mer II).

\section{Statistical Analysis}

For the descriptive analysis, the qualitative variables were described as numbers and percentages. The quantitative variables were described as means and standard deviations if they were normally distributed; otherwise, they were described as medians and interquartile ranges. For

\section{TABLE 2. Type of profession according to the revised} International Standard Classification of Occupations*

\begin{tabular}{ccc}
\hline Job Group & Former Rugby Players $(n=101)$ & Controls $(n=85)$ \\
\hline $0-1$ & 36 & 29 \\
\hline 2 & 17 & 8 \\
\hline 3 & 19 & 15 \\
\hline 4 & 8 & 5 \\
\hline 5 & 15 & 19 \\
\hline 6 & 3 & 2 \\
\hline $7-9$ & 3 & 7 \\
\hline
\end{tabular}

* There was no statistically significant difference (Fisher exact test, $p=0.24$ ). the bivariate analysis, the comparison between the former rugby players' characteristics and those of the controls relied on percentage comparison tests (chi-square test or Fisher exact test, depending on the condition for test application) for qualitative variables and on mean comparison tests (Student t-test or nonparametric Wilcoxon test if the criteria were not met for a Student t-test) for quantitative variables. The analysis of the primary endpoint (neck pain coded as yes or no) between the 2 groups was assessed in 2 stages. First, without any adjustment, we performed a bilateral chi-square test (or Fisher exact test, depending on the condition for test application). Then, we performed a multiple logistic regression analysis, taking into account potential confounding factors, with stepwise regression. For the analysis of secondary endpoints, quantitative variables to be investigated, including VAS and NDI scores, ranges of motion, and JOA score, were compared between the group of former rugby players and the control group without any adjustment, using a bilateral Student t-test or a nonparametric Wilcoxon test (if the criteria were not met for a Student t-test). History of cervical spine surgery, the binary qualitative variable to be investigated, was analyzed without any adjustment using a bilateral chi-square test (or Fisher exact test depending on the condition for test application). Regarding imaging data, the Matsumoto score was described, in each group, as nonzero grades for

TABLE 3. Characteristics of the 25 men from each group who underwent MRI*

\begin{tabular}{lccc}
\hline \multicolumn{1}{c}{ Characteristic } & $\begin{array}{c}\text { Former Rugby } \\
\text { Players }\end{array}$ & Controls & $\begin{array}{c}\mathrm{p} \\
\text { Value }\end{array}$ \\
\hline Age (yrs) & $40.3 \pm 4.0$ & $39.6 \pm 2.5$ & 0.52 \\
\hline Smoker & $13 / 25$ & $6 / 25$ & 0.11 \\
\hline $\begin{array}{l}\text { Weekly duration of } \\
\text { sport training (min) }\end{array}$ & $184.4 \pm 241.2$ & $108.2 \pm 157.7$ & 0.1359 \\
\hline Height (cm) & $183.4 \pm 8.2$ & $177.4 \pm 6.2$ & $\mathbf{0 . 0 0 4 8}$ \\
\hline BMl & $29.7 \pm 4.6$ & $25.3 \pm 4.1$ & $\mathbf{0 . 0 0 0 9}$ \\
\hline
\end{tabular}

* Bold type indicates statistical significance. 
each of the 4 elements (discopathy, disc protrusion, loss of disc height, foraminal stenosis) over the 6 intervertebral levels (from C2-3 to C7-T1). If the number of participants in a grade was too small $(<5)$, grades were combined to reach a minimum of 5 participants. The anteroposterior diameter (APD) of the vertebral canal, the medulla-tocervical canal ratio (MCR), and the cross-sectional area of the muscle analyzed, quantitative variables to be investigated, were analyzed in the same way as the previous quantitative clinical secondary endpoints (VAS score, ranges of motion, JOA score). The presence of medullary signal hyperintensity or a syringomyelia cavity on conventional MRI and the loss of perimedullary cerebrospinal fluid on at least 1 level on dynamic MRI (binary qualitative variables to be investigated) were analyzed without any adjustment using a bilateral chi-square test (or Fisher exact test, depending on the condition for test application).

\section{Results}

\section{Clinical Results}

Neck pain was reported by $51(50.50 \%)$ of the 101 former rugby players and 27 (31.76\%) of the 85 controls; the difference in rate of occurrence was statistically significant $(\mathrm{p}=0.01)$. The between-groups difference in VAS scores for neck pain intensity among those who complained of such pain was not statistically significant (mean 29.0 [SD 17.3] vs 26.7 [SD 15.8], respectively; $p=0.57$ ). There was also no significant difference between the 2 groups based on NDI scores (mean 6.6 [SD 4.2] vs 6.3 [SD 4.2]; $\mathrm{p}=$ 0.78 ). We noted 3 cases of disabling neck pain in former athletes and 1 case in the control group (defined by NDI score $>15)$.

Neurological abnormalities (corresponding to a JOA score of 15/17) were found in 1 former rugby player. He was a former front-row player who had had surgery twice during his professional career (an anterior cervical fusion had been performed each time) and had to stop playing rugby because of adjacent-level disease.

A comparison of clinical findings regarding range of motion between the groups revealed that former professional rugby players had significantly decreased mobility for rotations and tilts but not for flexion and extension (see Table 4 for details).

In the 101 former rugby players, 4 specific items related to rugby practice - field position, history of upgrade (person playing above his age category), number of selections in the national team, and length of career- were analyzed to investigate any significant association with later occurrence of neck pain, pain intensity, and/or NDI score. None of these 4 items was significantly related to more severe NDI scores or a greater number of pain complaints.

Finally, former rugby players had had more cervical spine surgery for degenerative disease (10 cases, 9.9\%) than controls $(0$ cases $)(p=0.002)$. All 10 rugby players concerned were treated for disc herniation and radiculopathy. All except one underwent surgical treatment during their rugby careers.

\section{Radiological Results}

We did not find any difference in Matsumoto score
TABLE 4. Comparison of cervical range of motion in former rugby players and controls*

\begin{tabular}{lccc}
\hline \multirow{2}{*}{ Movement } & \multicolumn{2}{c}{ Mean Values (cm) } & $p$ \\
\cline { 2 - 3 } & Former Rugby Players & Controls & Value \\
\hline Flexion & $0.58 \pm 1.48$ & $0.30 \pm 0.77$ & 0.79 \\
\hline Extension & $19.76 \pm 2.41$ & $20.41 \pm 2.12$ & 0.06 \\
\hline Left rotation & $11.80 \pm 1.85$ & $10.34 \pm 1.95$ & $<0.001$ \\
\hline Right rotation & $11.48 \pm 2.17$ & $11.10 \pm 1.19$ & $<0.001$ \\
\hline Left tilt & $12.47 \pm 1.90$ & $11.10 \pm 1.90$ & $<0.001$ \\
\hline Right tilt & $12.70 \pm 2.01$ & $11.43 \pm 1.93$ & $<0.001$ \\
\hline
\end{tabular}

* Bold type indicates statistical significance.

between the groups with respect to the average number of degenerative discs, disc protrusions, or narrowed disc spaces or in the average number of fused vertebrae. There were, however, significant differences in the presence of foraminal stenosis, the anteroposterior diameter (APD), and the medulla-to-cervical canal ratio (MCR) (see Table 5 for details). Former rugby players had much narrower canals than controls. The narrowest average APD found among former rugby players was $0.88 \mathrm{~cm}$ (SD $0.167 \mathrm{~cm})$ compared with $0.99 \mathrm{~cm}(\mathrm{SD} 0.130 \mathrm{~cm})$ in the control group $(\mathrm{p}=0.007)$. These values correspond to mean MCR values of 0.714 (SD 0.102) and 0.620 (SD 0.08), respectively $(\mathrm{p}<0.001)$. The predominant locations of the narrowest levels were at C5-6 and C6-7 in each group.

The study of muscle mass showed that former rugby players had a significantly greater mass than controls based on the calculated cross-sectional area of the splenius capitis $\left(5.00 \mathrm{~cm}^{2}\right.$ [SD $1.69 \mathrm{~cm}^{2}$ ] vs $3.17 \mathrm{~cm}^{2}$ [SD 0.91 $\left.\left.\mathrm{cm}^{2}\right], \mathrm{p}<0.001\right)$. These differences are illustrated in Figs. 1 and 2 .

Dynamic MRI sequences showed 6 dynamic spinal cord compressions in the former rugby player group (defined as loss of cerebrospinal fluid anterior and posterior to the spinal cord during flexion and/or extension of the neck) and 4 in the control group, a difference that was not statistically significant $(\mathrm{p}=0.48)$. We did not find any intramedullary lesions in either group.

TABLE 5. Comparison of MRI results in 25 former rugby players and 25 matched controls*

\begin{tabular}{lccc}
\hline \multicolumn{1}{c}{ Measure } & $\begin{array}{c}\text { Former Rugby } \\
\text { Players }\end{array}$ & Controls & $\begin{array}{c}p \\
\text { Value }\end{array}$ \\
\hline Discopathy & $4.16 \pm 1.52$ & $4.16 \pm 1.57$ & 1.00 \\
\hline Disc protrusion & $1.84 \pm 1.40$ & $1.76 \pm 1.01$ & 0.82 \\
\hline Disc space narrowing & $1.00 \pm 1.06$ & $0.50 \pm 1.08$ & 0.11 \\
\hline Foraminal stenosis & $1.44 \pm 1.19$ & $0.64 \pm 1.04$ & $\mathbf{0 . 0 1}$ \\
\hline Spinal block & 3 participants & 1 participant & 0.61 \\
\hline APD $(\mathrm{cm})$ & $0.880 \pm 0.167$ & $0.998 \pm 0.130$ & $\mathbf{0 . 0 0 7}$ \\
\hline MCR & $0.714 \pm 0.102$ & $0.620 \pm 0.0008$ & $<0.001$ \\
\hline
\end{tabular}

$\mathrm{APD}=$ anteroposterior diameter; $\mathrm{MCR}=$ medulla-to-cervical canal ratio.

* Values for discopathy, disc protrusion, disc space narrowing, and foraminal stenosis are mean Matsumoto scores with standard deviations. Bold type indicates statistical significance. 

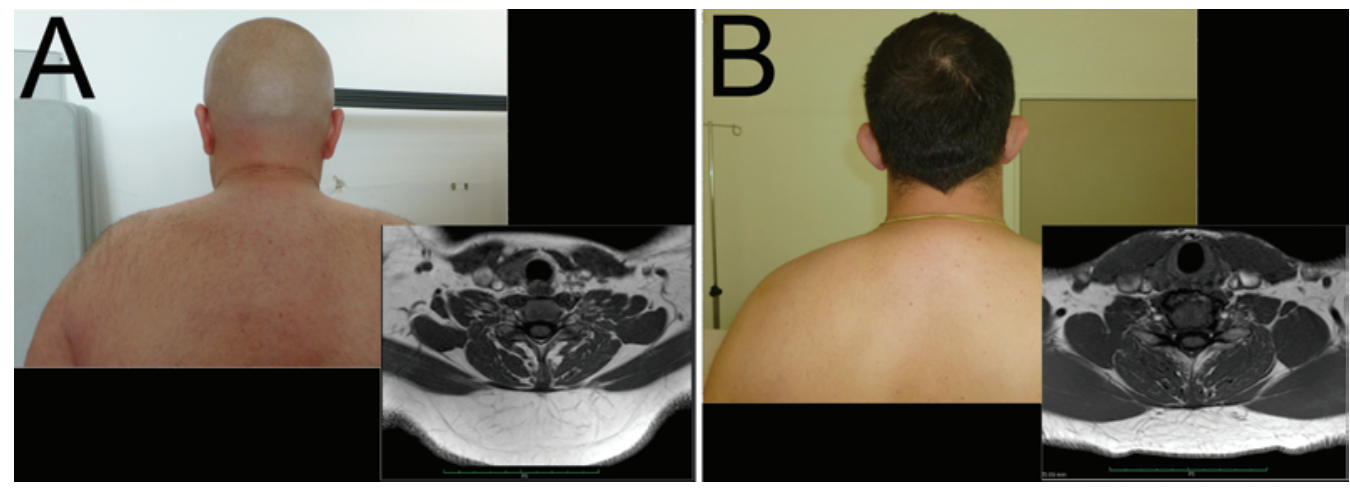

FIG. 1. Representative photographs and axial T1-weighted MR images (obtained at C6-7) showing differences in the paraspinal muscles of a heavy individual from the control group (A) and a former international rugby player of similar age, height, and weight (B) (control: age 39 years, height $1.74 \mathrm{~m}$, weight $110 \mathrm{~kg}$; former rugby player: age 40 years, height $1.76 \mathrm{~m}$, weight $114 \mathrm{~kg}$ ). Note the difference in muscle cross-sectional area. The MR images show that the control has more subcutaneous fat and less muscle than the former rugby player. Figure is available in color online only.

\section{Discussion}

This study has shown that former rugby players have decreased neck mobility and significantly greater prevalence of neck pain than controls. However, the intensity of these symptoms and the possible disability they entailed were comparable in both groups. A narrower cervical canal and more foraminal stenosis in the rugby group suggest that participation this sport may promote the development of degenerative lesions in young retired rugby players. Although only 1 case of neurological disease was noted in our 101 former rugby players, the rugby players had more often undergone surgery for a degenerative problem.

\section{Relationship Between Cervical Spine Degenerative Disease and High-Level Sports}

There are relatively few studies about degenerative disorders of the cervical spine related to intensive sports. $3,13,23$ The first work on this topic was published in 1982 by Sortland et al., who compared radiographs of 43 former international soccer players with radiographs of controls. The authors concluded that the onset of degenerative changes occurred 10 to 20 years earlier in soccer players than in the control group. ${ }^{23}$ Kurosawa et al. presented similar results in their work on 12 veteran amateur soccer players and found that the degenerative changes were consistent with the effect of repetitive microtrauma due to heading the ball. ${ }^{14} \mathrm{In}$ 2003, Kartal et al. studied the cervical spines of amateur soccer players. They made 2 types of comparisons: one between a group of soccer players and a group of healthy control subjects, and the other between retired soccer players and healthy control subjects of similar age. ${ }^{13}$ Despite the relatively small size of these groups, the studies demonstrated that former athletes may be more likely to have degenerative cervical lesions as well as a narrower cervical spinal canal. In addition, active soccer players had a more limited cervical range of motion compared with controls. Regarding rugby, only a few studies have indicated more severe degenerative lesions on imaging studies of individuals who have played this sport. Castinel et al., who reviewed static and dynamic MRI studies obtained in active male rugby players, found more frequent degenerative lesions (mainly degenerative discopathies) in older players. ${ }^{6}$ They underlined the role of dynamic MRI to assess the
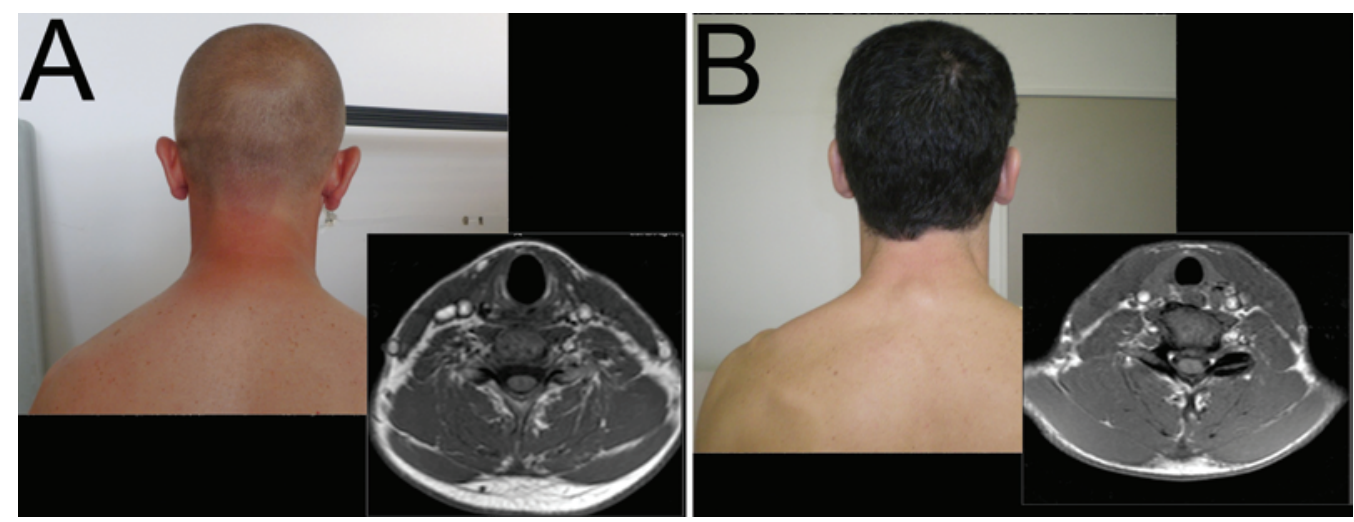

FIG. 2. Representative photographs and axial T1-weighted MR images (obtained at C6-7) showing differences in the paraspinal muscles of a slim individual from the control group (A) and a former international rugby player of similar age, height, and weight (B) (control: age 41 years, height $1.75 \mathrm{~m}$, weight $71 \mathrm{~kg}$; former rugby player: age 38 years, height $1.74 \mathrm{~m}$, weight $68 \mathrm{~kg}$ ). Like the heavier individuals shown in Fig. 1, these 2 men also have significant differences in subcutaneous fat and muscle. Again, the cross-sectional area of the paraspinal muscles is greater in the former rugby player than in the control. Figure is available in color online only. 
MCR, because most ratios that were initially assessed as intermediate with static MRI were subsequently assessed as abnormal with dynamic MRI. ${ }^{6}$ In a similar MRI study, Berge et al. compared 47 front-line rugby players (including 14 retired players) to 40 age-matched controls. They found more early degenerative alterations and narrower canals in rugby players at all ages. ${ }^{3}$

The overrepresentation of individuals who have undergone surgical operations in our study population could seem surprisingly high. Most of them had their surgical procedures during their sports career and resumed their rugby activity, indicating that spine surgery does not completely prohibit contact sports in professional athletes. ${ }^{12}$

\section{Bone and Joint Degeneration and Effects on Quality of Life of Former Athletes}

As suggested in similar studies on this topic, our results seem to confirm the relatively good tolerance of more serious osteoarticular lesions in high-level athletes. ${ }^{7,16,18,24}$ Nevertheless, the retired rugby players complained of pain more than the comparison group, although this symptom seemed rather well controlled among the former rugby players in this study. Some hypotheses can be proposed for this result. To our knowledge, there is no study on the relation between muscle condition and neck pain. The present study indicates that former rugby players have stronger paraspinal muscles than the general population. Muscle strengthening programs have been shown to be efficient in controlling chronic neck pain, ${ }^{25,29}$ and it has been shown that former high-level athletes maintain a high level of physical activity. ${ }^{16,19,21,28}$ Furthermore, the pain threshold seems higher in practicing or retired athletes than in the general population. ${ }^{10,21,24}$ In our study, the weekly duration of training for former rugby players was, on average, higher than for the men in the control group, although the difference was not statistically significant. These observations suggest that regularly practicing a sport could help to control pain, as has already been claimed by many au-

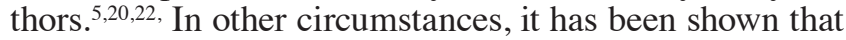
muscle trophicity (especially of the quadriceps femoris) could be a control factor for pain in gonarthrosis. ${ }^{11,26} \mathrm{Fi}-$ nally, the relatively high pain tolerance that we observed could be explained by the social, economic, and psychological situation of the former professional rugby players, all but one of whom had an active professional life.

\section{Limitations}

Our study has some limitations. The 2 groups studied were similar with respect to the main factors that promote the occurrence of premature degenerative cervical spine disease (type of job, smoking habit, and age). However, it remains possible that the differences we identified could have been due to another factor such as height or weight. This problem was discussed before the beginning of the study, and we chose not to match the participants on these characteristics because we wanted the control group to be a representative sample of the general population for these particular points. To our knowledge, there is no study that proves a relationship between height or weight and degenerative conditions of the cervical spine. Our study is also limited by the fact that rugby has been a professional sport in France only since 1995, and therefore we examined the first generation of professionals. With the evolution of the demands of the game and players' physical condition, it is uncertain whether our conclusions apply to current professional rugby players. ${ }^{8}$

Another limitation is that professional rugby players represent a very small proportion of the people playing rugby on a competitive basis. Maybe professionals are so superbly conditioned and anatomically/biomechanically suited to play the game that the impact of the game on the outcome parameters chosen is minimized or biased. Perhaps the game has a much greater effect on physical injuries in serious amateur rugby players, who actually represent the majority of people at risk. A study focusing on amateur rugby players could be very interesting to perform in the future.

Finally, our study population was rather young, with a mean age slightly over 40 years. Therefore, we should be cautious when drawing conclusions for the future. It is impossible to determine whether the condition of these former players will worsen with time or if the observed lesions and symptoms will stabilize after rugby participation has ended. Longer evaluation time would be necessary to evaluate these former rugby players more than 10 or 20 years after their retirement.

\section{Conclusions}

In this study we evaluated cervical spine degeneration in former rugby players and a comparison group from the general population in order to investigate the consequences of contact sports on the cervical spine. To the best of our knowledge, this is the largest such study performed to date for any contact sport. Our results indicate that, due to their former sporting activity, young retired professional rugby players have more degenerative cervical lesions and clinical consequences than the general population.

\section{Acknowledgments}

We thank Jean Claude Peyrin, MD, for the support of the French Rugby Federation's medical committee and Gael Arrandiga for support from Provale. We thank Martial Lousteau, MD (Clinique Saint Hilaire, Agen, France), Prof. Nicolas Sans, MD, PhD (Purpan University Hospital, Toulouse, France), and Marie Pierre Canale, radiology technician (Clinique Médipôle Garonne, Toulouse, France), for their help during MRI sessions. We are also grateful for the contributions of Benoit Chaput, MD, to this manuscript.

\section{References}

1. Albright JP, Moses JM, Feldick HG, Dolan KD, Burmeister LF: Nonfatal cervical spine injuries in interscholastic football. JAMA 236:1243-1245, 1976

2. Beck F, Tovar MC, Spilka S, Guignard R, Richard JB: Synthèse thématique: tabac et cigarette électronique. Observatoire Français des Drogues et Toxicomanies. (http://www. ofdt.fr/ofdtdev/live/produits/tabac/conso.html) [Accessed April 24, 2015]

3. Berge J, Marque B, Vital JM, Sénégas J, Caillé JM: Agerelated changes in the cervical spines of front-line rugby players. Am J Sports Med 27:422-429, 1999

4. Bohu Y, Julia M, Bagate C, Peyrin JC, Colonna JP, Thoreux $\mathrm{P}$, et al: Declining incidence of catastrophic cervical spine 
injuries in French rugby: 1996-2006. Am J Sports Med 37:319-323, 2009

5. Cassou B, Derriennic F, Monfort C, Norton J, Touranchet A: Chronic neck and shoulder pain, age, and working conditions: longitudinal results from a large random sample in France. Occup Environ Med 59:537-544, 2002

6. Castinel BH, Adam P, Milburn PD, Castinel A, Quarrie KL, Peyrin JC, et al: Epidemiology of cervical spine abnormalities in asymptomatic adult professional rugby union players using static and dynamic MRI protocols: 2002 to 2006 . Br J Sports Med 44:194-199, 2010

7. Elleuch MH, Guermazi M, Mezghanni M, Ghroubi S, Fki $\mathrm{H}$, Mefteh S, et al: Knee osteoarthritis in 50 former top-level soccer players: a comparative study. Ann Readapt Med Phys 51:174-178, 2008

8. Fuller CW, Sheerin K, Targett S: Rugby World Cup 2011: International Rugby Board injury surveillance study. Br J Sports Med 47:1184-1191, 2013

9. Garraway WM, Lee AJ, Hutton SJ, Russell EB, Macleod DA: Impact of professionalism on injuries in rugby union. Br $\mathbf{J}$ Sports Med 34:348-351, 2000

10. Geva N, Defrin R: Enhanced pain modulation among triathletes: a possible explanation for their exceptional capabilities. Pain 154:2317-2323, 2013

11. Highland TR, Dreisinger TE, Vie LL, Russell GS: Changes in isometric strength and range of motion of the isolated cervical spine after eight weeks of clinical rehabilitation. Spine (Phila Pa 1976) 17 (6 Suppl):S77-S82, 1992

12. Hsu WK: Outcomes following nonoperative and operative treatment for cervical disc herniations in National Football League athletes. Spine (Phila Pa 1976) 36:800-805, 2011

13. Kartal A, Yildiran I, Senköylü A, Korkusuz F: Soccer causes degenerative changes in the cervical spine. Eur Spine J 13:76-82, 2004

14. Kurosawa H, Yamanoi T, Yamakoshi K: Radiographic findings of degeneration in cervical spines of middle-aged soccer players. Skeletal Radiol 20:437-440, 1991

15. Lefevre B, Thierry P: Les premiers résultats de l'enquête 2010 sur les pratiques physiques et sportives en France. Ministère de la jeunesse, des sports et de la vie associative. (http://www.sports.gouv.fr/IMG/archives/pdf/StatInfo_01-11_decembre2010.pdf)

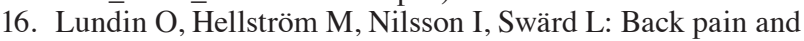
radiological changes in the thoraco-lumbar spine of athletes. A long-term follow-up. Scand J Med Sci Sports 11:103-109, 2001

17. Matsumoto M, Fujimura Y, Suzuki N, Nishi Y, Nakamura M, Yabe Y, et al: MRI of cervical intervertebral discs in asymptomatic subjects. J Bone Joint Surg Br 80:19-24, 1998

18. Oztürk A, Ozkan Y, Ozdemir RM, Yalçin N, Akgöz S, Saraç $\mathrm{V}$, et al: Radiographic changes in the lumbar spine in former professional football players: a comparative and matched controlled study. Eur Spine J 17:136-141, 2008

19. Pihl E, Zilmer K, Kullisaar T, Kairane C, Mägi A, Zilmer M: Atherogenic inflammatory and oxidative stress markers in relation to overweight values in male former athletes. Int J Obes (Lond) 30:141-146, 2006

20. Scheef L, Jankowski J, Daamen M, Weyer G, Klingenberg M, Renner J, et al: An fMRI study on the acute effects of exercise on pain processing in trained athletes. Pain 153:17021714,2012
21. Schmitt H, Brocai DR, Lukoschek M: High prevalence of hip arthrosis in former elite javelin throwers and high jumpers: 41 athletes examined more than 10 years after retirement from competitive sports. Acta Orthop Scand 75:34-39, 2004

22. Sitthipornvorakul E, Janwantanakul P, Purepong N, Pensri P, van der Beek AJ: The association between physical activity and neck and low back pain: a systematic review. Eur Spine J 20:677-689, 2011

23. Sortland O, Tysvaer AT, Storli OV: Changes in the cervical spine in association football players. Br J Sports Med 16:80-84, 1982

24. Spector TD, Harris PA, Hart DJ, Cicuttini FM, Nandra D, Etherington J, et al: Risk of osteoarthritis associated with long-term weight-bearing sports: a radiologic survey of the hips and knees in female ex-athletes and population controls. Arthritis Rheum 39:988-995, 1996

25. Taimela S, Takala EP, Asklöf T, Seppälä K, Parviainen S: Active treatment of chronic neck pain: a prospective randomized intervention. Spine (Phila Pa 1976) 25:1021-1027, 2000

26. Thorstensson CA, Petersson IF, Jacobsson LTH, Boegård TL, Roos EM: Reduced functional performance in the lower extremity predicted radiographic knee osteoarthritis five years later. Ann Rheum Dis 63:402-407, 2004

27. Torg JS, Vegso JJ, Sennett B, Das M: The National Football Head and Neck Injury Registry. 14-year report on cervical quadriplegia, 1971 through 1984. JAMA 254:3439-3443, 1985

28. Vingård E, Sandmark H, Alfredsson L: Musculoskeletal disorders in former athletes. A cohort study in 114 track and field champions. Acta Orthop Scand 66:289-291, 1995

29. Ylinen J, Takala EP, Nykänen M, Häkkinen A, Mälkiä E, Pohjolainen T, et al: Active neck muscle training in the treatment of chronic neck pain in women: a randomized controlled trial. JAMA 289:2509-2516, 2003

\section{Author Contributions}

Conception and design: Brauge, Delpierre, Adam, Bernard, Roux. Acquisition of data: Brauge, Adam. Analysis and interpretation of data: Brauge, Roux. Drafting the article: Brauge. Critically revising the article: Brauge, Delpierre, Sol, Roux. Reviewed submitted version of manuscript: Brauge, Roux. Approved the final version of the manuscript on behalf of all authors: Brauge. Statistical analysis: Brauge, Delpierre. Administrative/technical/material support: Brauge, Sol. Study supervision: Brauge, Bernard.

\section{Supplemental Information}

\section{Previous Presentation}

Portions of this work were presented in abstract form at the Société Française de Chirurgie rachidienne (SFCR) Congress in Nice, France, on June 14, 2013.

\section{Correspondence}

David Brauge, Pôle Neuroscience, Neurochirurgie, Hopital Purpan, Place du Docteur Baylac, TSA 40031, Toulouse 31059, France.email: brauge.d@chu-toulouse.fr. 